\title{
Efficacy and Safety Results of the Afatinib Expanded Access Program
}

Edward S. Kim - Balazs Halmos • Ingrid F. Kohut - Taral Patel •

Regan D. Rostorfer - Alexander I. Spira - Agnieszka Cseh •

John McKay · Gudrun Wallenstein · Kathryn F. Mileham

Received: February 9, 2017 / Published online: April 10, 2017

(C) The Author(s) 2017. This article is an open access publication

\section{ABSTRACT}

Introduction: Afatinib is an oral, irreversible ErbB family blocker approved for first-line treatment of metastatic epidermal growth factor receptor $(E G F R)$ mutation-positive non-small cell lung cancer (NSCLC). The expanded access program (EAP) allowed early access to afatinib and provided additional data on its safety, tolerability, and efficacy.

Enhanced Content To view enhanced content for this article go to http://www.medengine.com/Redeem/ 4A08F06035246488.

\section{E. S. Kim $(\bowtie)$ - K. F. Mileham}

Department of Solid Tumor Oncology and Investigational Therapeutics, Levine Cancer Institute, Carolinas HealthCare System, Charlotte, NC, USA

e-mail: edward.kim@carolinashealthcare.org

\section{B. Halmos}

Division of Hematology/Oncology, Columbia

University, New York, NY, USA

I. F. Kohut

Division of Hematology/Oncology, Department of Medicine, Abramson Cancer Center, University of Pennsylvania, Philadelphia, PA, USA

T. Patel

Medical Oncology/Hematology, Zangmeister

Center, Columbus, OH, USA
Methods: The afatinib EAP was an open-label, multicenter, single-arm program in the United States that treated and followed patients with locally advanced or metastatic NSCLC harboring EGFR mutations. Afatinib $40 \mathrm{mg}$ was administered orally once daily until discontinuation due to disease progression, adverse events (AEs), or transition to commercially available drug.

Results: Three hundred twenty-two patients received $\geq 1$ dose of afatinib. Most patients had received prior therapies. Drug-related AEs occurred in $89.4 \%$ of patients, including $7.8 \%$ with serious AEs. The most common afatinib-related AEs (all grades) were diarrhea

R. D. Rostorfer

University of Florida Health Cancer Center, Orlando Health, Orlando, FL, USA

\section{A. I. Spira}

Virginia Cancer Specialists Research Institute, Fairfax, VA, USA

A. Cseh

Boehringer Ingelheim RCV GmbH \& Co KG,

Vienna, Austria

\section{J. McKay}

Boehringer Ingelheim Pharmaceuticals, Inc., Ridgefield, CT, USA

G. Wallenstein

Boehringer Ingelheim Pharma GmbH \& Co KG, Ingelheim am Rhein, Germany 
$(77.0 \%)$ and rash (36.0\%). Dose reductions occurred in $31.1 \%$ of patients. Discontinuation rates due to diarrhea $(1.6 \%)$ or rash/acne $(0.3 \%)$ were low. Efficacy data were collected and analyzed when available, with $17.1 \%$ and $69.9 \%$ of patients achieving objective response and disease control, respectively, in this highly pretreated population.

Conclusions: No additional or unexpected safety concerns were revealed, and afatinib demonstrated antitumor activity in a heavily pretreated NSCLC patient population in a routine clinical setting.

Trial Registration: ClinicalTrials.gov Identifier: NCT01649284.

Funding: Boehringer Ingelheim Pharmaceuticals, Inc.

Keywords: Afatinib; EGFR; Expanded access program; Non-small cell lung cancer; Safety

\section{INTRODUCTION}

Afatinib $\left(\right.$ GILOTRIF $^{\circledR}$, Boehringer Ingelheim; Ingelheim, Germany) is an oral, irreversible ErbB family blocker approved by the US Food and Drug Administration (FDA) for first-line treatment of metastatic non-small cell lung cancer (NSCLC) in patients whose tumors harbor epidermal growth factor receptor (EGFR) mutations, specifically exon 19 deletions (Del19) or exon 21 (L858R) substitutions, as identified by an FDA-approved test [1]. Afatinib is also approved for the treatment of patients with metastatic, squamous NSCLC progressing after platinum-based chemotherapy [1]. It has been evaluated in several NSCLC clinical trials, including tyrosine kinase inhibitor (TKI)-naïve and TKI-exposed patients [2-4]. Results from two global phase 3 trials, LUX-Lung 3 and LUX-Lung 6, demonstrated significant progression-free survival (PFS) benefit with afatinib versus cisplatin/pemetrexed and cisplatin/gemcitabine, respectively, as first-line therapy among patients with common EGFR mutations (Del19/L858R) [5, 6]. In both studies, a significant overall survival (OS) benefit was also observed with afatinib in patients with Del19 mutations [7].
Expanded access, or "compassionate use," makes investigational drugs available to patients in the United States who are ineligible for ongoing clinical trials [8]. This expanded access program (EAP) was developed to provide afatinib access before FDA approval for patients with locally advanced or metastatic NSCLC harboring EGFR mutations, regardless of the line of therapy (not limited to Del19 or L858R mutations in the first-line setting, as currently indicated). The aim of this study was to collect additional information on afatinib safety, tolerability, and efficacy in a real-world clinical setting.

\section{METHODS}

\section{Patients/Program Design}

The afatinib EAP was an open-label, multicenter, single-arm program conducted at 66 US sites. Adult patients with locally advanced or metastatic NSCLC harboring EGFR mutations (identified per the institution's testing methodology), adequate organ function, and an Eastern Cooperative Oncology Group performance status (ECOG PS) of $0-2$ were eligible regardless of line of therapy. Patients with symptomatic brain metastases were excluded from participation, but patients with previously treated asymptomatic brain metastases were eligible, provided they had stable disease for $\geq 4$ weeks on stable doses of medication.

Patients were instructed to take a single oral dose of afatinib $40 \mathrm{mg}$ with a glass of water at approximately the same time each day, with no food for $\geq 3 \mathrm{~h}$ before and $\geq 1 \mathrm{~h}$ after taking afatinib. Dose escalation was prohibited. Dose reductions in 10-mg steps were allowed based on tolerability. Adverse events (AEs) were categorized and graded using the National Cancer Institute Common Terminology Criteria for Adverse Events, version 3.0. For patients with any grade $\geq 3$ treatment-related AEs, prolonged grade 2 diarrhea ( $\geq 48 \mathrm{~h}$ ), grade $\geq 2$ worsening renal function, or acute onset and/or unexplained worsening of pulmonary symptoms, afatinib treatment was withheld while supportive care was administered or clinical 
assessment was completed. After the AE fully resolved, returned to baseline, or improved to grade 1, afatinib was reinstituted at a dose reduced by $10 \mathrm{mg}$; the dose could not be increased. For unrelated AEs, the treating physician could pause medication for $\leq 14$ days without dose reduction. Patients were discontinued from the EAP if afatinib was paused $>6$ weeks.

Patients were followed monthly until discontinuation due to disease progression, unacceptable AEs, or transition to commercially available drug. The EAP was stopped when afatinib became commercially available. Palliative radiation therapy was permitted for symptom control.

The protocol received institutional review board approval, and the study was conducted in accordance with the principles of the Declaration of Helsinki of 1964, as revised in 2013 and the International Conference on Harmonisation guidelines for Good Clinical Practice. All patients provided written informed consent.

\section{Assessments}

The primary objective was to provide afatinib access to patients who might benefit from it. There were no primary or secondary efficacy objectives, but disease assessments were performed per local standard of care. Safety was assessed descriptively.

\section{Statistical Analysis}

Exploratory, descriptive analyses of demographic, safety, and efficacy data were planned based on the treated set (all patients who were dispensed medication and were documented to have taken $\geq 1$ afatinib dose), with two subgroups divided by previous TKI exposure.

\section{RESULTS}

\section{Patients}

From July 2012 to March 2014, 371 patients were enrolled and 322 patients were treated with $\geq 1$ afatinib dose (Fig. 1). Common reasons for discontinuation were disease progression (53.4\%) and EAP completion (28.3\%). After the EAP was stopped, patients were transitioned to commercial product, if appropriate. Baseline demographic characteristics were generally representative of NSCLC patients with EGFR mutations (Table 1$)$; most $(82.9 \%)$ had common EGFR mutations (Del19/L858R). T790M mutation or exon 20 insertion was present in 25 (7.8\%) and 22 (6.8\%) patients, respectively; 23/25 patients with T790M mutations also had other EGFR mutations. The mean age was 64.6 years, and most patients were female (68.6\%), white (73.6\%), and had an ECOG PS of 0 or $1(87.0 \%)$. Most patients received prior therapy, with $87.3 \%$ of patients previously exposed to a TKI (primarily erlotinib), $67.1 \%$ to systemic chemotherapy, and $8.7 \%$ to another anticancer therapy. Afatinib was first-line therapy for $23(7.1 \%)$ patients, second-line therapy for $85(26.4 \%)$ patients, third-line therapy for 71 $(22.0 \%)$ patients, and later-line therapy for 143 $(44.4 \%)$ patients. A total of $86(26.7 \%)$ patients had brain metastases present at screening.

\section{Exposure}

Median treatment duration was 86 days (maximum, 393 days). Nearly half of the patients (48.1\%) received afatinib for $\geq 90$ days. Dose reductions occurred in $100(31.1 \%)$ patients, with 98 patients reduced from 40 to $30 \mathrm{mg}$ (including 30 patients subsequently reduced to $20 \mathrm{mg}$ ) and two patients reduced from 40 to $20 \mathrm{mg}$.

\section{Safety}

Most patients (96.3\%) experienced an AE, with $89.4 \%$ experiencing $\geq 1$ drug-related $\mathrm{AE}$ (Table 2). Serious AEs occurred in $33.9 \%$ of patients, with $7.8 \%$ considered related to afatinib. Treatment discontinuation due to AEs was reported for $12.1 \%$ of patients; $5.3 \%$ discontinued due to afatinib-related AEs.

The most common drug-related AEs were diarrhea (77.0\%) and rash (36.0\%); the majority were grade 1 or 2 . Afatinib-related grade 3 AEs occurred in $18.0 \%$ of patients, including 
diarrhea (9.9\%); rash (1.9\%); dehydration (1.6\%); stomatitis, mucosal inflammation, and fatigue (each 1.2\%); and acute renal failure $(0.9 \%)$. Grade 4 afatinib-related AEs occurred in 4 (1.2\%) patients (peripheral edema, multiorgan failure, dehydration, and acute renal failure; $n=1$ each), but only one required discontinuation (peripheral edema).

The majority of afatinib-related serious AEs were grade 3 , with diarrhea $(n=9)$, dehydration $(n=6)$, and acute renal failure $(n=3)$ the most common. Disease progression was responsible for most fatal events; no fatal event was considered related to afatinib.

Supportive care measures were implemented for $66.8 \%$ of patients with diarrhea and $33.9 \%$ with rash. Dose reductions occurred in $31.1 \%$ of patients: $16.8 \%$ due to diarrhea, and $3.7 \%$ due to rash. With dose reduction and treatment, few patients discontinued because of diarrhea $(1.6 \%)$ or rash $(0.3 \%)$.

\section{Efficacy}

While no efficacy objectives were prespecified, data were collected and analyzed where possible. Afatinib demonstrated antitumor activity in this heavily pretreated population in which $44.4 \%$ of patients had received $\geq 3$ prior therapies. The population included patients with common and non-sensitizing EGFR mutations. Overall, $69.9 \%$ of patients achieved disease control (Table 3). Although subgroup comparisons must be interpreted cautiously due to small sample sizes and patient heterogeneity, TKI-naïve patients generally experienced better efficacy versus TKI-exposed patients. Most responses (89.1\%) were observed within the first 16 weeks from start of treatment, and median duration of tumor response (4.1 months) was similar for TKI-naïve and TKI-exposed patients. Although many patients (28.3\%) transitioned to commercial drug and were not fully

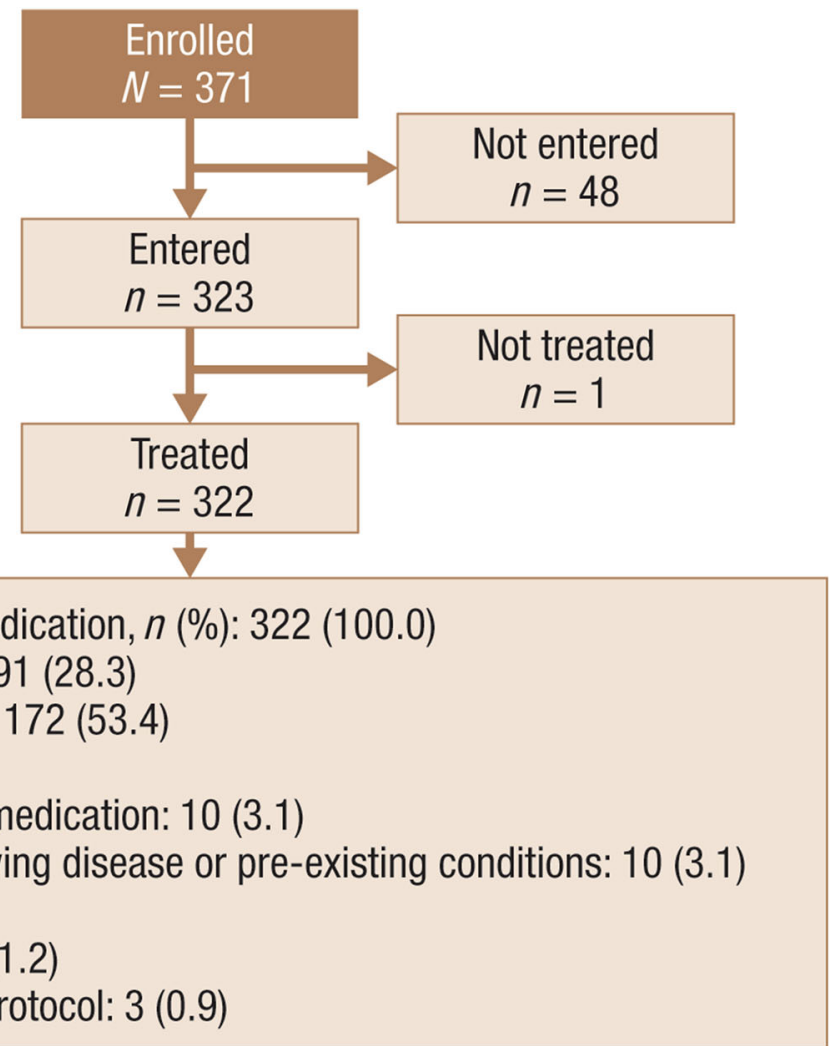

Fig. 1 Disposition of patients (enrolled set). ${ }^{a}$ EAP expanded access program, $A E$ adverse event. ${ }^{a}$ Enrolled set included all patients who signed the informed consent. ${ }^{\mathrm{b}}$ Transition to commercially available drug 
Table 1 Demographic Data (Treated Set)

\begin{tabular}{|c|c|}
\hline Characteristic & $\begin{array}{l}\text { Afatinib } 40 \mathrm{mg} \\
N=322\end{array}$ \\
\hline \multicolumn{2}{|l|}{ Gender, $n(\%)$} \\
\hline Female & $221(68.6)$ \\
\hline Male & $101(31.4)$ \\
\hline \multicolumn{2}{|l|}{ Race, $n(\%)^{a}$} \\
\hline White & $237(73.6)$ \\
\hline Asian & $56(17.4)$ \\
\hline Black/African American & $24(7.5)$ \\
\hline Native Hawaiian/Pacific Islander & $2(0.6)$ \\
\hline American Indian/Alaska Native & $2(0.6)$ \\
\hline Age, mean (SD), years & $64.6(12.1)$ \\
\hline Min; $\max$ & $35 ; 94$ \\
\hline \multicolumn{2}{|l|}{ Smoking status, $n$ (\%) } \\
\hline Never smoked & $201(62.4)$ \\
\hline Ex-smoker & $113(35.1)$ \\
\hline Currently smokes & $8(2.5)$ \\
\hline \multicolumn{2}{|l|}{ Baseline ECOG score, $n$ (\%) } \\
\hline 0 & $112(34.8)$ \\
\hline 1 & $168(52.2)$ \\
\hline 2 & $42(13.0)$ \\
\hline \multicolumn{2}{|l|}{ TKI status, $n(\%)$} \\
\hline Exposed $^{\mathrm{b}}$ & $281(87.3)$ \\
\hline Naïve & $41(12.7)$ \\
\hline First-line afatinib & $23(7.1)$ \\
\hline Common EGFR mutation, $n$ (\%) & $267(82.9)$ \\
\hline $\begin{array}{l}\text { Uncommon } E G F R \text { mutation, } \\
n(\%)^{c}\end{array}$ & $55(17.1)$ \\
\hline $\mathrm{T} 790 \mathrm{M}$ & $25(7.8)$ \\
\hline Exon 20 insertions & $22(6.8)$ \\
\hline G719S, G719A, G719C & $20(6.2)$ \\
\hline L861Q & $13(4.0)$ \\
\hline S768I & $4(1.2)$ \\
\hline Other-not specified & $13(4.0)$ \\
\hline
\end{tabular}

Table 1 continued

\begin{tabular}{ll}
\hline Characteristic & $\begin{array}{l}\text { Afatinib } \mathbf{4 0 ~} \mathbf{~ m g}, \\
N=\mathbf{3 2 2}\end{array}$ \\
\hline $\begin{array}{l}\text { Time since first diagnosis, mean } \\
\text { (SD), months }\end{array}$ & $32.8(28.0)$ \\
Min; max & $1 ; 152$ \\
Histologic classification, $n$ (\%) & \\
Predominantly adenocarcinoma & $303(94.1)$ \\
NOS & $8(2.5)$ \\
Predominantly squamous cell & $7(2.2)$ \\
carcinoma & $4(1.2)$ \\
Large cell/undifferentiated & \\
carcinoma & \\
Clinical stage at initial diagnosis, $n(\%)^{\mathrm{d}}$ \\
0-IIB & $54(16.8)$ \\
IIIA & $24(7.5)$ \\
IIIB & $23(7.1)$ \\
IV & $218(67.7)$ \\
\hline$S D$
\end{tabular}

$S D$ standard deviation, ECOG Eastern Cooperative Oncology Group, TKI tyrosine kinase inhibitor, EGFR epidermal growth factor receptor, NOS not otherwise specified

${ }^{a}$ Data missing for one patient

b All except two patients received erlotinib

${ }^{c}$ Patients can appear in $\geq 1$ category

${ }^{\mathrm{d}}$ Data missing for three patients

documented until disease progression, median PFS was 3.6 months and was longer among TKI-naïve patients. Due to early censoring, OS data were immature.

\section{DISCUSSION}

This EAP provided early access to afatinib and collected additional prospective safety and efficacy information. Despite most patients being heavily pretreated, the safety profile was consistent with earlier trials of afatinib monotherapy, with no new safety concerns $[2,5,6]$. The most common AEs were gastrointestinal and dermatologic, which is 
Table 2 AE Overall Summary (Treated Set)

\begin{tabular}{ll}
\hline Number of patients, $n$ (\%) & $\begin{array}{l}\text { Afatinib } \mathbf{4 0 ~} \mathbf{~ m g}, \\
N=322\end{array}$ \\
\hline Any AE & $310(96.3)$ \\
Drug-related AEs ${ }^{\mathrm{a}}$ & $288(89.4)$ \\
AEs reported in $>10 \%$ of treated & patients \\
(all grades; grade 3/4) & \\
Diarrhea & $248(77.0) ; 32(9.9)$ \\
Rash & $116(36.0) ; 6(1.9)$ \\
Mucosal inflammation & $54(16.8) ; 4(1.2)$ \\
Stomatitis & $43(13.4) ; 4(1.2)$ \\
Nausea & $41(12.7) ; 1(0.3)$ \\
Dry skin & $40(12.4) ; 2(0.6)$ \\
Fatigue & $36(11.2) ; 4(1.2)$ \\
Paronychia & $34(10.6) ; 0$ \\
AEs leading to discontinuation & $39(12.1)$ \\
Drug-related AEs leading to & $17(5.3)$ \\
discontinuation & $69(21.4)$ \\
AEs leading to dose reduction & $109(33.9)^{\mathrm{d}}$ \\
Serious AEs &
\end{tabular}

$A E$ adverse event

${ }^{a}$ Investigator defined

b Grade 4 drug-related AEs occurred in four patients, including one patient each with peripheral edema, multi-organ failure, dehydration, and acute renal failure; no grade 5 AEs were reported

c A patient may be counted in $\geq 1$ seriousness criterion

d Afatinib-related serious AEs occurred in $7.8 \%$ of patients

${ }^{\mathrm{e}}$ No deaths were considered by the investigators to be related to afatinib. Most deaths were due to disease progression similar to those reported for other EGFRtargeted therapies. Most cases of diarrhea and rash/acne were adequately managed by pausing treatment, dose reduction, and supportive treatment and infrequently required discontinuation. These findings suggest that, with proper dose optimization and diarrhea and rash/acne management, patients can remain on afatinib treatment.

Although this EAP was not designed with specific efficacy aims, afatinib demonstrated antitumor activity, with disease control achieved in $69.9 \%$ of patients and objective tumor response in $17.1 \%$. This response rate is slightly higher compared to the LUX-Lung 1 trial of afatinib after failure of erlotinib, gefitinib, or both [2]. PFS durations were shorter compared to LUX-Lung 3 (11.1 months) and LUX-Lung 6 (11.0 months) [5, 6]; however, only $7.1 \%$ of patients in this EAP received afatinib as first-line treatment, and many patients were not fully documented until disease progression. Patients also had an extensively longer time since first diagnosis in this EAP.

Findings of this EAP must be tempered against several limitations. Subgroup analyses must be interpreted with caution due to small sample size and widely different durations of drug exposure. EGFR mutation testing was not standardized across sites, which may have resulted in varying sensitivity levels for identification of mutations between sites. Lastly, although the majority of patients were alive at the end of the program, the EAP was not designed to follow patients through death, and OS data are immature and not reliably interpretable.

\section{CONCLUSION}

The results of the afatinib EAP confirm that, in a broad patient population, afatinib is not associated with unexpected safety signals and has safety and antitumor activity profiles similar to those observed in earlier clinical trials. 
Table 3 Efficacy End Points (Treated Set)

\begin{tabular}{|c|c|c|c|}
\hline & $\begin{array}{l}\text { Overall, } \\
N=322\end{array}$ & $\begin{array}{l}\text { TKI-naïve, }{ }^{a} \\
n=41\end{array}$ & $\begin{array}{l}\text { TKI-exposed, } \\
n=281\end{array}$ \\
\hline \multicolumn{4}{|l|}{ Response, $^{\mathrm{b}} n(\%)[95 \% \mathrm{CI}]$} \\
\hline \multirow[t]{2}{*}{ Disease control $^{c}$} & $225(69.9)$ & $34(82.9)$ & $191(68.0)$ \\
\hline & {$[64.5-74.8]$} & {$[67.9-92.8]$} & {$[62.2-73.4]$} \\
\hline \multirow[t]{2}{*}{ Objective response $^{\mathrm{d}}$} & $55(17.1)$ & $14(34.1)$ & $41(14.6)$ \\
\hline & {$[13.1-21.6]$} & {$[20.1-50.6]$} & {$[10.7-19.3]$} \\
\hline \multirow[t]{2}{*}{ Stable disease } & $170(52.8)$ & $20(48.8)$ & $150(53.4)$ \\
\hline & {$[47.2-58.4]$} & {$[32.9-64.9]$} & {$[47.4-59.3]$} \\
\hline $\begin{array}{l}\text { Median duration of objective response, }{ }^{\mathrm{d}} \text { months } \\
{[95 \% \mathrm{CI}]}\end{array}$ & $4.1[3.4-5.3]$ & $3.4[2.1-\mathrm{NE}]$ & $4.2[3.0-5.8]$ \\
\hline Median duration of disease control, ${ }^{c}$ months $[95 \% \mathrm{CI}]$ & $4.7[4.4-5.2]$ & $5.9[3.5-\mathrm{NE}]$ & $4.6[4.2-5.0]$ \\
\hline Median PFS, months [95\% CI] & $3.6[3.1-4.2]$ & $5.8[3.4-8.1]$ & $3.6[2.9-3.9]$ \\
\hline
\end{tabular}

$T K I$ tyrosine kinase inhibitor, $C I$ confidence interval, $N E$ not estimable, $P F S$ progression-free survival

a Includes 23 patients treated with first-line afatinib

b Tumor response is based on clinical, radiologic, or other assessment

c Disease control included complete response + partial response + stable disease

d Objective response included complete response + partial response

\section{ACKNOWLEDGEMENTS}

We would like to acknowledge the contributions of all participants of the afatinib EAP, especially the patients and their treating physicians. This manuscript was previously presented as an abstract/poster at Chicago Multidisciplinary Symposium in Thoracic Oncology; October 30-November 1, 2014; Chicago, IL, USA. Alexander I. Spira reports grant support from Boehringer Ingelheim to conduct the present study. Journal article processing charges were funded by the study sponsor, Boehringer Ingelheim Pharmaceuticals, Inc. (BIPI). All named authors meet the International Committee of Medical Journal Editors (ICMJE) criteria for authorship for this manuscript, take responsibility for the integrity of the work as a whole, and have given final approval to the version to be published. The authors received no direct compensation related to the development of the manuscript. All authors had full access to all of the data in this study and take complete responsibility for the integrity of the data and accuracy of the data analysis. Writing, editorial support, and formatting assistance were provided by Lauren Fink, PhD, of MedErgy, which was contracted and funded by BIPI. BIPI was given the opportunity to review the manuscript for medical and scientific accuracy as well as intellectual property considerations.

Disclosures. Edward S. Kim reports consulting for AstraZeneca, Boehringer Ingelheim, Celgene, and Eli Lilly. Balazs Halmos reports consulting fees from AstraZeneca, Boehringer Ingelheim, Celgene, and Genentech. Alexander I. Spira reports grant support and fees from Novartis and Roche and grant support from Boehringer Ingelheim. Agnieszka Cseh, John McKay, and Gudrun Wallenstein are employees of Boehringer Ingelheim. Kathryn F. Mileham has served on an advisory board for Boehringer 
Ingelheim, has consulted with Covidien, and reports research funding from Celgene. Ingrid F. Kohut, Taral Patel, and Regan D. Rostorfer have nothing to disclose.

Compliance with Ethics Guidelines. The protocol received institutional review board approval, and the study was conducted in accordance with the principles of the Declaration of Helsinki of 1964, as revised in 2013 and the International Conference on Harmonisation guidelines for Good Clinical Practice. All patients provided written informed consent.

Data Availability. The datasets generated during and/or analyzed during the current study are available from the corresponding author on reasonable request.

Open Access. This article is distributed under the terms of the Creative Commons Attribution-NonCommercial 4.0 International License (http://creativecommons.org/licenses/ by-nc/4.0/), which permits any noncommercial use, distribution, and reproduction in any medium, provided you give appropriate credit to the original author(s) and the source, provide a link to the Creative Commons license, and indicate if changes were made.

\section{REFERENCES}

1. GILOTRIF $^{\circledR}$ (afatinib) tablets, for oral use [package insert]. Ridgefield, CT: Boehringer Ingelheim Pharmaceuticals Inc.; 2016.

2. Miller VA, Hirsh V, Cadranel J, et al. Afatinib versus placebo for patients with advanced, metastatic non-small-cell lung cancer after failure of erlotinib, gefitinib, or both, and one or two lines of chemotherapy (LUX-Lung 1): a phase $2 \mathrm{~b} / 3$ randomised trial. Lancet Oncol. 2012;13:528-38.

3. Schuler $\mathrm{MH}$, Planchard D, Yang JCH, et al. Interim analysis of afatinib monotherapy in patients with metastatic NSCLC progressing after chemotherapy and erlotinib/gefitinib (E/G) in a trial of afatinib plus paclitaxel versus investigator's choice chemotherapy following progression on afatinib monotherapy. J Clin Oncol. 2012;30(suppl):Abst 7557.

4. Hoffknecht P, Tufman A, Wehler T, et al. Efficacy of the irreversible ErbB family blocker afatinib in epidermal growth factor receptor (EGFR) tyrosine kinase inhibitor (TKI)-pretreated non-small cell lung cancer patients with brain metastases or leptomeningeal disease. J Thorac Oncol. 2014;10:156-63.

5. Sequist LV, Yang JCH, Yamamoto N, et al. Phase III study of afatinib or cisplatin plus pemetrexed in patients with metastatic lung adenocarcinoma with EGFR mutations. J Clin Oncol. 2013;31:3327-34.

6. Wu YL, Zhou C, Hu CP, et al. Afatinib versus cisplatin plus gemcitabine for first-line treatment of Asian patients with advanced non-small-cell lung cancer harbouring EGFR mutations (LUX-Lung 6): an open-label, randomised phase 3 trial. Lancet Oncol. 2014;15:213-22.

7. Yang JCH, Wu YL, Schuler M, et al. Afatinib versus cisplatin-based chemotherapy for EGFR mutation-positive lung adenocarcinoma (LUX-Lung 3 and LUX-Lung 6): analysis of overall survival data from two randomised, phase 3 trials. Lancet Oncol. 2015;16:141-51.

8. US Food and Drug Administration. Expanded Access (Compassionate Use). Available from: http://www. fda.gov/NewsEvents/PublicHealthFocus/Expanded AccessCompassionateUse/ucm20080392.htm. Accessed January 27, 2017. 